\title{
CLINICAL AUDIT
}

\section{An audit of "do not attempt resuscitation" decisions in two district general hospitals: do current guidelines need changing?}

\author{
Dylan Harris, Rachel Davies
}

Postgrad Med J 2007;83:137-140. doi: 10.1136/pgmi.2006.050260

See end of article for authors' affiliations

.....................

Correspondence to: Dr D Harris, Nevill Hall Hospital, Abergavenny, South Wales, 15 Llwyn Y Grant Terrace, Penylan, Cardiff CF23 9EW, UK. dgharris@doctors.org.uk

Revised 25 September 2006 Accepted 26 September 2006
Introduction: Doctors in all specialties are involved in making "do not attempt resuscitation" (DNAR) decisions; this can be a difficult and challenging process. Guidelines exist to provide an ethical and legal framework for the process and documentation of these decisions.

Objective: To audit the documentation of resuscitation decisions in a sample of medical inpatients from two district general hospitals.

Method: A retrospective case note audit of 50 medical inpatients, in which a DNAR decision had been made (28 from hospital 1, 22 from hospital 2).

Results: Average age was 78.9 years ( $48 \%$ male:52\% female). In both hospitals DNAR decisions were usually discussed with relatives (84\%), documented in nursing notes $(100 \%)$ and made by senior team members (90\%). Although the decision was usually dated and clearly documented (98\%), abbreviations were commonly used in hospital $2(45.5 \%$ vs $0 \%$ in hospital $1, p<0.05)$. Decisions regarding other treatment were not consistently documented $(78.6 \%$ and $72.7 \%$, respectively) and there was little evidence that decisions were reviewed (14.3\% and $31.8 \%$ ). The decision was rarely discussed with the patient ( $6 \%$ of all patients), although $66 \%$ of patients were not in a position to have a discussion.

Conclusions: Specific forms for recording DNAR decisions improve the clarity of documentation. Current recommendations to discuss resuscitation with patients are controversial and not followed. However, many patients are not in a position to hold a discussion when the need arises and the guidelines should advocate early discussion during a hospital admission in patients where this is appropriate, prior discussion with family and/or wider use of advanced directives.
A fter the introduction of cardiopulmonary resuscitation (CPR) in the 1960s its use has been widened to involve many situations where it has been shown to have little benefit. In the UK, there are joint guidelines on decisions relating to CPR from the British Medical Association, the UK Resuscitation Council and the Royal College of Nursing and these were updated in 2001, partly to incorporate the implications of the Human Rights Act 1998 (in particular, the right to life (article 2) and the right to hold opinions and receive information (article 10)). ${ }^{12}$

The guidelines acknowledge that it is essential to identify patients for whom CPR is inappropriate and those who competently refuse it. ${ }^{1}$ It is appropriate to consider a do not attempt resuscitation (DNAR) order where:

- attempting CPR will not restart the patient's heart and breathing,

- where there is no clear benefit in restarting the patient's heart and breathing, and

- where the expected benefit is outweighed by the burdens.

\section{METHODS}

We identified 10 key standards in the guidelines (see below) and retrospectively audited the case notes for evidence that these standards had been followed. The audit was conducted on patients in whom a DNAR decision had been made on a general medical ward in two district general hospitals.

1. A discussion with competent patients about CPR (or that the patient indicated a desire to avoid discussion).
2. Discussion/involvement of the patient's family/carers (particularly of patients lacking mental capacity).

3. The consultant responsible for the patients care was aware of and approved the decision.

4. The entry in the medical notes should be clearly documented and dated.

5. To avoid confusion "do not attempt resuscitation" or similar should be documented and not abbreviations such as "not for 2222" or "NFR".

6. Reasons for the DNAR decision should be stated.

7. The decision should be made by the most senior member of the team available.

8. The decision should be recorded in the nursing notes.

9. A DNAR decision applies only to CPR and documentation should reflect whether other active treatment should be given.

10. Decisions about resuscitation must be reviewed regularly: if the decision is indefinite this should be stated.

One hospital (hospital 1) used a standard yellow communication sheet to record DNAR decisions, while the other relied on clear documentation written as a medical entry in the case notes.

If it was clear from the case notes that the patient had been unable to participate in discussion (eg, due to confusion or coma) we noted this as "unable" and equally if it was clear a

Abbreviations: CPR, cardiopulmonary resuscitation; DNAR, do not attempt resuscitation; GMC, General Medical Council 
Table 1 Baseline characteristics of the audit sample

\begin{tabular}{llll}
\hline & Hospital 1 & Hospital 2 & Combined result \\
\hline Number of patients audited & 28 & 22 & 50 \\
Sex, male: female & $16(57 \%): 12(43 \%)$ & $8(36.5 \%): 14(63.6 \%)$ & $24(48 \%): 26(52 \%)$ \\
Age (years), mean (SD, range) & $77.8(12.3,44-94)$ & $80.3(9.6,53-95)$ & $78.9(11.1,44-95)$ \\
\hline
\end{tabular}

discussion with relatives/carers was attempted, but not possible (eg, relatives uncontactable).

\section{RESULTS}

The total number of case notes audited was 50 with combined average patient age of 78.9 years and combined sex ratio $48 \%$ male: $52 \%$ female (table 1 ).

Table 2 shows the combined and individual audit results for each hospital. The audited samples in both hospitals showed that DNAR decisions were usually discussed with the patients' relatives/carers (84\% combined cases), that there was evidence that the consultant had been involved in the process $(100 \%$ combined cases) and a senior team member had made the initial decision (90\% cases). Although the decision was dated and clearly documented in both hospitals (98\% combined cases), abbreviations were commonly used in hospital 2 (45.5\% vs $0 \%$ in hospital $1, p<0.05)$. A record of the decision was always recorded in the nursing notes (100\% cases).

However, decisions regarding other active treatment were not consistently documented in either hospital sample $(78.6 \%$ and $72.7 \%$, respectively) and there was little evidence that the resuscitation decision was reviewed or documented to be indefinite ( $14.3 \%$ and $31.8 \%$ of cases, respectively).

The most significant deviation in clinical practice from the guidelines was discussion with the patient: this took place in only $6 \%$ of cases where the patient would have been able to do so $(3.6 \%$ and $9.1 \%$ of cases, respectively). Of further importance, two thirds of patients were not in a position to have a conversation regarding resuscitation (for reasons such as cognitive impairment, coma, etc). Out of these cases, only 4 $(8 \%)$ had either made an advanced directive which included resuscitation or had previously expressed their opinion regarding resuscitation to their family (only 8 of all the patients audited had a known advanced directive or had previously made their wishes known to a carer/family member).

\section{DISCUSSION}

The main differences between the standard of the documentation between the two hospitals (ie, use of abbreviations and reasons given for the decision) are likely to be explained by the use of a specific DNAR form in hospital 1 , this inference is supported by other studies which have found improved documentation when a specific form is used. ${ }^{3}$

In both hospitals audited, the most consistent deviation from the recommendations of the guidelines was that of discussion with the patient (even accounting for those who were unable to participate in discussion). Although current UK guidelines suggest that doctors do not need to discuss "every eventuality with all patients" they also state that decisions regarding potential benefits and burdens of CPR "should be discussed with competent patients". ${ }^{1}$ General Medical Council (GMC) guidelines on withdrawing and withholding life prolonging treatment also give unclear advice about involvement of patients in CPR decisions. ${ }^{45}$ Whether doctors should discuss resuscitation with terminally ill patients therefore remains a highly controversial issue. ${ }^{67}$

\section{Medical arguments for discussing resuscitation with patients}

It may be argued that poor communication and lack of information leads to poor patient satisfaction, symptom management and compliance as well as increased fear and anxiety. ${ }^{7}$ Equally, discussion about CPR is as important as discussion about any other treatment in terminally ill patients. ${ }^{7}$ Furthermore, doctors are inaccurate when predicting patients' views and wishes (a 30-40\% inconsistency has been found). ${ }^{8}$ Importantly, patients are unlikely to disclose their preferences spontaneously, this has important implications as there is some evidence that patients feel that doctors have bias towards using life prolonging techniques where they would not want them attempted and there have been reports of patients being successfully resuscitated and stating that they had not wanted $\mathrm{CPR}^{8}{ }^{9}$

\section{Medical arguments against discussing resuscitation with patients}

By contrast, discussion may cause distress and many patients have difficulty understanding risk/benefit concepts. ${ }^{3}{ }^{10}$ Furthermore, it may force patients to confront the inevitability of their fate (with potentially negative consequences) and discussion requires patients to make a choice when in reality they have no choice-in certain settings where chances of success are low and futility high (eg, hospice or continuing care facility) it can be argued that a non-resuscitation policy of the institution is appropriate without the need for individual discussion. ${ }^{11}$ This may avoid the situation where a patient requests CPR despite explanation of its futility: the guidelines acknowledge that a doctor cannot be required to give treatment contrary to their clinical judgement and if a doctor feels that the harm of the discussion outweighs the benefits there should be no moral imperative to discuss CPR. ${ }^{161213}$ Doctors may also experience difficulty discussing these issues (one study showed that $72.8 \%$ of doctors find discussions stressful ${ }^{14}$ ) and there is a reduction in the documentation of DNAR decisions where patient discussion is mandatory. ${ }^{3}$

\section{Patient perspectives on CPR}

Patients may have strong views on their treatment and CPR, notably in 2004 the GMC was challenged on its guidance on "Withholding and withdrawing life prolonging treatment". Although the claimant, Mr Burke, was concerned about doctors withdrawing artificial nutrition and hydration as his degenerative neurological disease progressed, the initial ruling that doing so was unlawful and in breach of his human rights had wider implication which would have included patients demanding CPR against the judgement of health care professionals. ${ }^{15}$ Although the GMC won its appeal against the judgement, this remains a delicate legal area.

Although qualitative aspects of CPR decisions have been researched, the limited research available is conflicting (potentially because different sample populations may give different opinions eg, elderly people as opposed to patients with cancer or interviewing a doctor as opposed to a nurse). Most studies have found that most of the patients thought that doctors 


\begin{tabular}{|c|c|c|c|}
\hline Audit standard & $\begin{array}{l}\text { Hospital 1, } \\
\text { n (\%) }\end{array}$ & $\begin{array}{l}\text { Hospital 2, } \\
\text { n (\%) }\end{array}$ & $\begin{array}{l}\text { Combined } \\
\text { result (\%) }\end{array}$ \\
\hline Standard 1: patient & $\begin{array}{l}1(3.6) \\
U=12(429)\end{array}$ & $2(9.1)$ & 6 \\
\hline $\begin{array}{l}\text { discussion } \\
\text { Standard 2: relative/ }\end{array}$ & $\begin{array}{l}U=12(42.9) \\
25(89.3)\end{array}$ & $\begin{array}{l}U=11(50) \\
17(77.3)\end{array}$ & $\begin{array}{l}U=66 \\
84\end{array}$ \\
\hline carer discussion & $U=1(3.6)$ & $U=1(4.5)$ & $\mathrm{U}=4$ \\
\hline $\begin{array}{l}\text { Standard 3: consultant } \\
\text { involvement }\end{array}$ & $28(100)$ & $22(100)$ & 100 \\
\hline $\begin{array}{l}\text { Standard 4: clear dated } \\
\text { documentation }\end{array}$ & $28(100)$ & 21 (95.5) & 98 \\
\hline $\begin{array}{l}\text { Standard 5: not for CPR } \\
\text { written in full }\end{array}$ & $28(100)$ & $10(45.5)$ & 76 \\
\hline $\begin{array}{l}\text { Standard 6: reasons } \\
\text { stated }\end{array}$ & $28(100)$ & $17(77.3)$ & 90 \\
\hline $\begin{array}{l}\text { Standard 7: decision by } \\
\text { senior team member }\end{array}$ & $27(96.4)$ & $18(81.8)$ & 90 \\
\hline $\begin{array}{l}\text { Standard 8: recorded in } \\
\text { nursing notes }\end{array}$ & $28(100)$ & $22(100)$ & 100 \\
\hline $\begin{array}{l}\text { Standard 9: decision } \\
\text { regarding other active } \\
\text { treatment }\end{array}$ & $22(78.6)$ & $16(72.7)$ & 76 \\
\hline $\begin{array}{l}\text { Standard 10: decision } \\
\text { reviewed }\end{array}$ & $4(14.3)$ & $7(31.8)$ & 22 \\
\hline
\end{tabular}

CPR, cardiopulmonary resuscitation.

$\mathrm{U}$, patient unable to participate in discussion/relative or carer unable or unavailable to participate in discussion.

should discuss CPR with them although this is not a consistent finding. ${ }^{10}{ }^{17-19}$ It has also been shown that patients find such discussion distressing or are unable to retain and recall it. ${ }^{17}{ }^{18}$ Furthermore, although patients may express a wish to discuss CPR with their doctor, far fewer actually want to be involved in making the final decision. ${ }^{10} 18$

Aside to whether patients want to discuss CPR, do they actually want it? Patients are less likely than doctors to want CPR - one study of older people found that the majority would not want to be "kept alive at all costs". ${ }^{18}{ }^{20}$ A re-emerging theme from qualitative studies has been the optimistic view of the general public on the success of CPR (up to 96\% overestimate its effectiveness), ${ }^{142021}$ largely attributable to its successful portrayal in the media. This may account for some of the reported discrepancy between patients and doctors regarding CPR preference: when patients are given accurate information they are significantly less likely to request a preference for it. ${ }^{1321} 22$ Making advance directives does not seem to increase patient preference for CPR. ${ }^{18}$

Finally, although it is a contentious issue as to whether resuscitation should be discussed with patients, what is evident from this audit is the proportion of patients who are actually unable to discuss resuscitation when the decision was made ( $66 \%$ in this sample, $51 \%$ in other studies ${ }^{23}$ ). Only $16 \%$ of the total sample of patients had either made an advanced directive or had made their views on resuscitation known to their family or carer. The timing of discussion is also therefore important and if it is to take place will need to be done either at any earlier stage in a patients' admission or from previous discussions with family (including formal declaration as an advance directive).

\section{CONCLUSION}

Guidelines on CPR provide a framework to guide the process and documentation of resuscitation decisions and were largely followed in this audit sample. Specific forms for recording DNAR decisions seem to improve the clarity of the documentation.

Whether resuscitation decisions should be discussed with patients is controversial and is balanced between the ethical principles of a desire to do good, not to do harm and respect for patients' autonomy.
In selected patients who have expressed a desire to be actively involved in their management, communication may be improved if resuscitation is discussed with the patient in the context of treatment plans (rather than a separate consultation). For these patients discussion should not be given as a "choice" of options (unless the benefits and risks of CPR are not actually clear cut), but an explanation of the decision (as medically there may be no "choice" and patients do not seem to want to make the final decision themselves). However, to be actively involved patients need to be better educated about the reality of the success of $\mathrm{CPR}$, explained in terms that they can understand.

Regardless of whether a consensus is reached regarding the appropriateness of discussing resuscitation decisions, many patients are not in a position to have a discussion when it arises and the guidelines should also advocate proactive discussion with appropriate patients early during admission and wider use of prior discussion with family around the issues of resuscitation including formal declaration of a preference against resuscitation recorded in an advance directive.

\section{Learning points}

- It is appropriate to consider making a DNAR order when CPR is unlikely to be successful, of no clear benefit or where the expected benefit is outweighed by the burdens.

- The joint Resuscitation Guidelines provide an ethical and legal framework for the process and documentation of resuscitation decisions.

- Resuscitation decisions should be clearly documented (without use of abbreviations) with reasons given, made by a senior team member with consultant involvement, documented in nursing notes, include reference to the appropriateness of other treatment and be reviewed regularly.

- Current recommendations to discuss resuscitation with patients are controversial and not followed; many patients are not practically able to have a discussion when the need arises.

- If discussion is to take place this should occur at proactively at an early stage or from prior discussion with family including declaration of preference against resuscitation in an advance directive.

\section{Authors' affiliations}

Dylan Harris, Nevill Hall Hospital, Abergavenny, South Wales, Cardiff, UK Rachel Davies, Royal Glamorgan Hospital, Llantrissant, South Wales, Cardiff, UK

Competing interests: None.

\section{REFERENCES}

1 British Medical Association, UK Resuscitation Council and Royal College of Nursing. Decisions relating to cardiopulmonary resuscitation. British Medical Association, London, 2001.

2 Stewart K, Spice C, Rai GS. Where now we resuscitation decisions? Age Ageing 2003:32:143-8.

3 Diggory $P$, Shire $L$, Griffith $D$, et al. Influence of guidelines on CPR decisions: an audit of clerking proforma. Clin Med 2004;4:424-5.

4 General Medical Council. Good medical practice: withholding and withdrawing life-prolonging treatments: good practice in decision making. London, GMC, 2002.

5 Regnard C, Randall F. A framework for making advance decisions on resuscitation. Clin Med 2005;5:354-60.

6 Manisty C, Waxham J. Doctors should not discuss resuscitation with terminally ill patients: FOR. BMJ 2003;327:614-15.

7 Higginson IJ. Doctors should not discuss resuscitation with terminally ill patients: AGAINST. BMJ 2003;327:615-16.

8 Hayward $M$. Cardiopulmonary resuscitation: are practitioners being realistic? Br J Nurs 1999;12:810-14. 
9 Vandrevala T, Hampson SE, Daly T, et al. Dilemmas in decision-making about cardiopulmonary resuscitation-a focus group study of older people. Soc Sci Med 2006;62: 1579-93.

10 Frank C, Heylan DK, Chen B, et al. Determining resuscitation preferences of elderly inpatients: a review of the literature. CMAJ 2003;169:795-9.

11 Conroy SP, Luxton T, Dingwall R, et al. Cardiopulmonary resuscitation in continuing care settings: time for a rethink. BMJ 2006;332:479-82.

12 Reid C, Jeffrey D. Do not attempt resuscitation decisions in a cancer centre: addressing difficult ethical and communication issues. Br J cancer 2002;86:1057-60.

13 Florin D. Decisions about cardiopulmonary resuscitation. BMJ 1994;308:1653-4.

14 Scott G, Mulgrew E, Smith T. Cardiopulmonary resuscitation: attitudes and perceptions of junior doctors. Hosp Med 2003;64:425-8.

15 Samanta A, Samanta J. End of life decisions. BMJ, 331:1284-5.

16 Mohindra R. Obligations to treat, personal autonomy, and artificial nutrition and hydration. Clin Med 2006:6:271-3.

17 Morgan R, King D, Prajapati C, et al. Views of elderly patients and their relatives on cardiopulmonary resuscitation. BMJ 1994;308:1677-8.
18 Laakkonen ML, Pitkala KH, Strandberg TE, et al. Living Will, Resuscitation preferences, and attitudes towards life in an aged population. Gerontology 2004;50:247-54.

19 Fidler $\mathrm{H}$, Thompson C, Freeman A, et al. Barriers to implementing a policy not to attempt resuscitation in acute medical admissions: prospective, cross sectional study of a successive cohort. BMJ 2006:332:461-2

20 Catt S, Blanchard M, Addington-Hall J, et al. Older adults' attitudes to death, palliative treatment and hospice care. Palliative Med 2005; 19:402-10.

21 Murphy DJ, Burrows D, Santilli S, et al. The influence of the probability of survival on patients' perspectives regarding cardiopulmonary resuscitation. NEJM 1994;330:545-9.

22 Kerridge IH, Pearson SA, Rolfe IE, et al. Impact of written information on knowledge and preferences for cardiopulmonary resuscitation. MJA 1999:171:239-42.

23 Fiddler $\mathbf{H}$, Thompson $\mathrm{C}$, Freeman $\mathrm{A}$, et al. Barriers to implementing a policy not to attempt resuscitation in acute medical admissions: prospective, cross sectional study of a successive cohort. BMJ 2006;332:461-2. 